Journal of Patient-Centered

$1-25-2016$

\title{
Stinging Nettle: the Bad, the Good, the Unknown
}

\section{Dennis J. Baumgardner}

Follow this and additional works at: https://aah.org/jpcrr

Part of the Alternative and Complementary Medicine Commons, Complex Mixtures Commons, Disorders of Environmental Origin Commons, and the Skin and Connective Tissue Diseases Commons

\section{Recommended Citation}

Baumgardner DJ. Stinging nettle: the bad, the good, the unknown. J Patient Cent Res Rev. 2016;3:48-53. doi: 10.17294/2330-0698.1216

Published quarterly by Midwest-based health system Advocate Aurora Health and indexed in PubMed Central, the Journal of Patient-Centered Research and Reviews (JPCRR) is an open access, peer-reviewed medical journal focused on disseminating scholarly works devoted to improving patient-centered care practices, health outcomes, and the patient experience. 


\title{
Stinging Nettle: the Bad, the Good, the Unknown
}

\author{
Dennis J. Baumgardner, MD \\ Department of Family Medicine, Aurora University of Wisconsin Medical Group, Aurora Health Care, Milwaukee, WI; \\ Center for Urban Population Health, Milwaukee, WI
}

\begin{abstract}
Stinging nettle (Urtica dioica) is native to most of the United States. It has a characteristic description and distribution in the environment. Physical contact with numerous tiny needlelike hairs present on leaves and stems of this plant may result in a contact urticarial dermatitis due to chemical and mechanical irritation triggered by skin penetration of the hairs. The manifestations are self-limited in humans and may be treated by washing the skin, topical preparations and oral antihistamines. Explanation of the natural history of these encounters to the patient is helpful in reducing the sometimes significant anxiety. Preparations and extracts of stinging nettle have been proposed for treatment of a variety of inflammatory and other disorders including osteoarthritis, benign prostatic hypertrophy, allergic rhinitis and asthma, bleeding problems and diabetes. While in vitro studies have shown that stinging nettle possesses a number of potentially beneficial anti-inflammatory and modulating properties, beneficial effects have often not been confirmed by well-designed clinical trials. Further study, perhaps with novel types of extracts, are needed to determine the clinical utility of this plant in human inflammatory-related conditions and diabetes mellitus. (J Patient-Centered Res Rev. 2016;3:48-53.)
\end{abstract}

Keywords Urtica dioica; urticaria; plants, toxic; plant extracts; trichomes; nettles; anti-inflammatory

Stinging nettle (Urtica dioica), or simply "nettle," is one example of a large number of plants (and related chemicals) that have both potentially beneficial and harmful effects on human health. ${ }^{1}$ This common perennial weed is found in most portions of the continental United States, especially the eastern half. It is abundant in Wisconsin, where it prefers rich, moist soils, particularly along waterways and in bottomlands, neglected yards, waste dumps, upland forest edges, fencerows, and railroad and highway right-of-ways.,3 Stands are typified by large, dense colonies, which may enlarge yearly via new shoots from underground rhizomes. It is sometimes cultivated.

The plants grow up to 4 to 6 feet high with fibrous, unbranched stems. Green, slender, heart- or elm-shaped, serrated, rough-textured leaves, 2 to 3 inches long, grow at regular intervals along each stem (Figure 1A). Clusters of thin, "non-showy" yellow-green flowers in which the leaves attach to the stem appear in warm-weather

Correspondence: Dennis J. Baumgardner, MD, Aurora Sinai Medical Center, 1020 N. 12th Street, \#4180, Milwaukee, WI, 53233, T: 414-219-5191, F: 414-219-3116, Email: dennis.baumgardner@aurora.org months (Figure 1B). ${ }^{2,3}$ Leaves and stems are covered with copious minute stinging hairs called trichomes (Figure 2A) to ward off plant predators. Many of these hollow hairs "resemble a hypodermic needle," with a sharp-pointed, bulbous tip that bends to penetrate the skin when touched (Figure 2B). Inflammatory chemicals are injected into the skin from a gland at the base of the
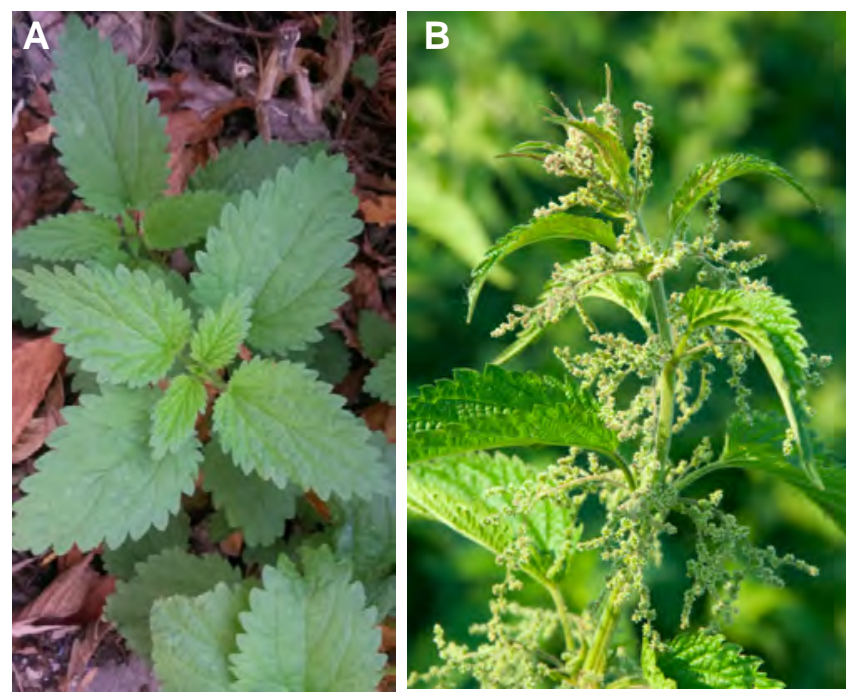

Figure 1. Photographs of stinging nettle (Urtica dioica). A: Nonflowering young plant. (Photograph courtesy of Bill Schultz.) B: Mature flowering plant. 
hairs through the broken bulb at the tip..$^{2-5}$ This action results in a contact urticarial dermatitis in many persons.

Stinging nettle plants are to be distinguished from the ubiquitous goldenrod (associated with hay fever in many persons). The latter also grow in large clusters, but have more slender, generally lance-shaped leaves and terminal, generally upright flowers of showy yellow that bloom in late summer and fall (Figure 3). Goldenrods lack stinging hairs and are not a contact hazard.

This brief review discusses the local skin reaction to stinging nettle exposure and what is currently known about the potential or purported benefits of stinging nettle and its extracts on human health regarding osteoarthritis, allergic rhinitis, benign prostatic hypertrophy (BPH), diabetes and other disorders.
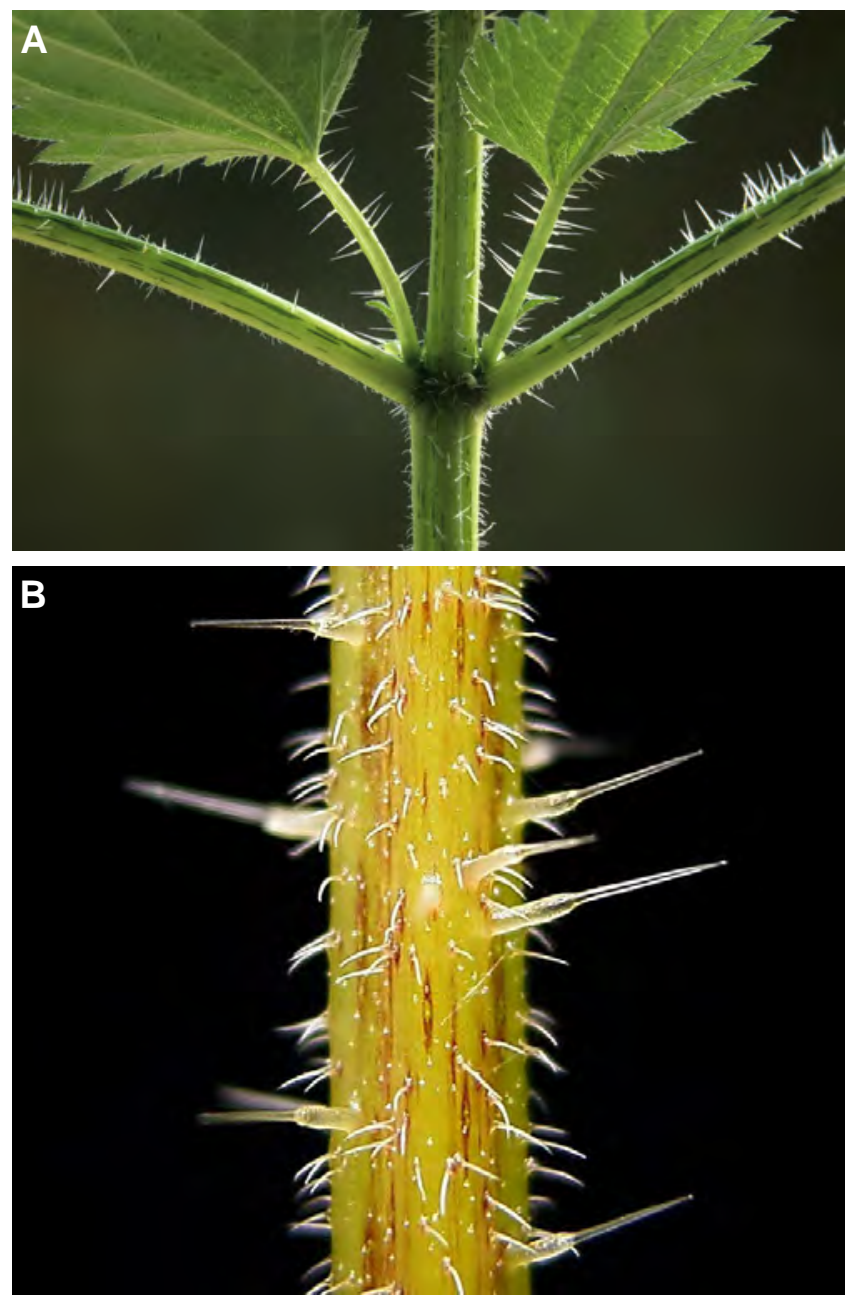

Figure 2. Close-up photographs of stinging nettle (Urtica dioica). A: Note the abundant, tiny stinging hairs on the leaves and stems. B: Trichome of stinging nettle.

\section{Illustrative Case}

A generally healthy 54-year-old man was brought to the infirmary of a summer Boy Scout camp located in northern Wisconsin with concerns regarding a burning, stinging red rash on both arms and a swollen right hand. The man was fearful about the rapid onset of the symptoms and the potential for further damage to his upper extremities. He denied any known hazardous exposures or any recent new medications, lotions, clothing or change in his hygiene or skin care routines. His accompanying companions, however, indicated that his bare arms had come in contact with stinging nettle plants during attempts to remove some debris around the camp. His only regular medication was lisinopril for mild hypertension. He had no known allergies, nor had he ever experienced anything like the present disorder.

Physical examination revealed an alert, oriented obese male who was quite anxious. He was diaphoretic and mildly tachycardic. Both arms and his right (dominant) hand revealed a mild, patchy, erythematous urticarial rash. There was mild generalized soft tissue swelling in his right hand. The remainder of his physical examination was unremarkable. The patient was treated with the available antihistamine, diphenhydramine, following a diagnosis of contact urticarial dermatitis due to stinging nettle. He was reassured regarding the natural history of this exposure and the excellent prognosis. His anxiety was significantly relieved with the explanation. An inquiry the following morning indicated that his symptoms were essentially resolved and he was doing well.

\section{Stinging Nettle Dermatitis}

Physical contact with stinging nettle often results in a nonimmunologic-induced contact urticarial or irritant dermatitis. There is an immediate burning, stinging, pruritic sensation in the exposed area, followed within minutes by a blanching urticarial rash (Figure 4). ${ }^{2,5}$ The sensitivity of humans to stinging nettle contact appears to be variable, ${ }^{4}$ and many do not seek medical attention because of the short-lived duration of the symptoms (minutes to hours). ${ }^{5}$ Some individuals experience symptoms for greater than 12 hours. ${ }^{6}$ All ages appear to be affected. There has been a report of a Turkish neonate with generalized urticaria associated with maternal application of water boiled with stinging nettle to her 


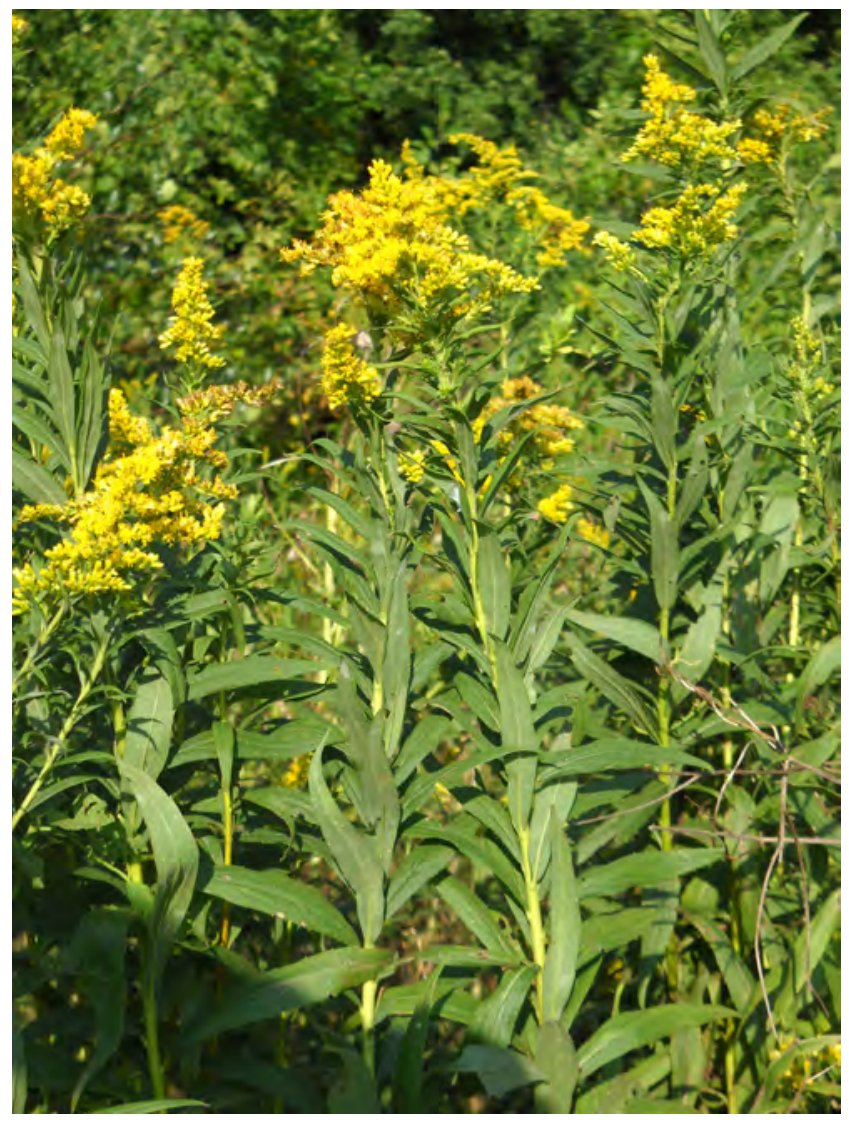

Figure 3. Goldenrod (Solidago Canadensis, one of many Solidago species) is to be differentiated from stinging nettle. This plant is associated with hay fever, but the fine hairs at the top of stems do not sting.

nipples (apparently not on the advice of any health professional). Specific immunoglobulin E levels for stinging nettle were high in the infant and the mother. ${ }^{7}$

The mechanism of action of toxicity following the penetration of human skin and injection of liquid from the base glands of the nettle hairs as described earlier may be both biochemical and mechanical. Based on animal experiments, some of the trichomes may remain in the skin after contact and cause direct mechanical irritation. ${ }^{2}$ The biochemical indicators of inflammation injected by the nettle hairs appear to include histamine, serotonin, acetylcholine and leukotrienes $\mathrm{B}_{4}$ and $\mathrm{C}_{4} ;{ }^{5}$ however, it has been suggested that there may be additional (yet unknown) substances in nettle fluid directly toxic to nerves or capable of secondary release of other mediators. ${ }^{6}$ In humans, the urticarial manifestations are self-limited and non-

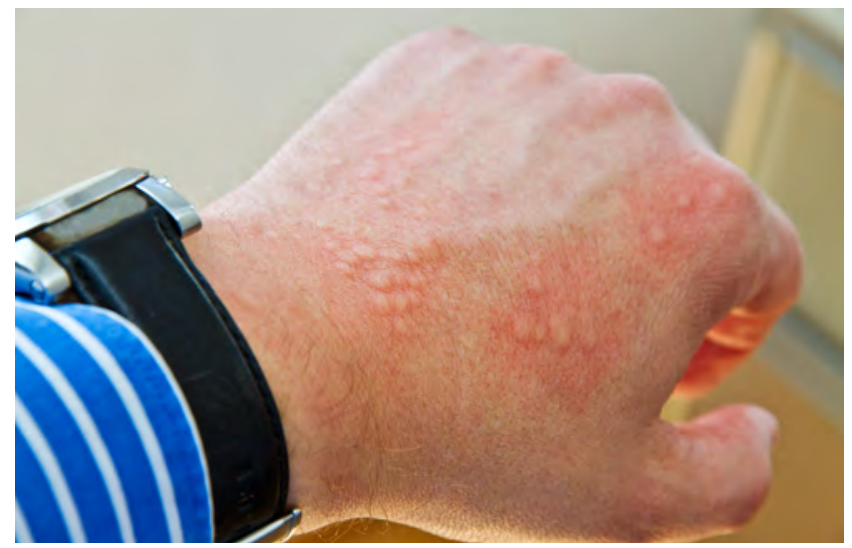

Figure 4. Example of stinging nettle dermatitis.

life-threatening. However, short-haired dogs may be poisoned while walking the patches of stinging nettle due to the very significant load of penetrated hair spicules. Symptoms may include weakness, muscle tremors and dyspnea. ${ }^{4}$

There is no standardized treatment for persons with stinging nettle contact dermatitis. ${ }^{5}$ Anecdotally, washing the involved area thoroughly with water as soon as possible, avoiding rubbing the area or exposing to heat, and using oral antihistamines seem to hasten relief. One may attempt to remove nettle hairs from the skin by lightly applying a very sticky tape, such as duct tape, and quickly removing it. ${ }^{8}$ Topical agents that may be of some relief include cool compresses, aloe vera or a paste made of water and baking soda.

\section{Potential Beneficial Uses of Urtica dioica and Extracts}

History: Beneficial uses for stinging nettle date to ancient times. Before its medicinal use, extracts of the plant were used for fabric weaving as early as the Bronze Age. Nettle fibers were used to make paper. ${ }^{9}$ Similarly, this plant has long been consumed as food. Leaves, especially young ones, may be cooked (never eaten raw to avoid irritation) and eaten as a fresh leaf, a soup additive or in tea, beer and wine. Nettle is a source of iron and other minerals, vitamin C, carotenoids and essential amino and fatty acids. ${ }^{10}$ Individuals wishing to handle nettle plants for cooking must take care to avoid direct skin contact by wearing gloves and long sleeves. 
Systemic and topical medicinal uses of nettle have been described for 2,000 years and include treatments for bites, wounds and poisonings. It was smoked to treat asthma, and teas or juices were prepared for pregnancy complications and to augment breast milk production and hair growth. ${ }^{9}$

The online database Natural Medicines lists stinging nettle preparations as "possibly effective" for osteoarthritis, but "insufficient reliable evidence to rate” nettle for other possible uses. ${ }^{9}$

Osteoarthritis: A recent Cochrane review of the effects of various topical herbal remedies on osteoarthritis was unable to conclude that topical stinging nettle improved symptoms based on low-quality single trials. ${ }^{11}$ Three of the most often-cited references include small numbers of patients. One retrospective interview study of 18 self-selected patients suggested improvement in joint or muscular pain by use of nettle, mostly by rubbing, beating or touching (apparently) fresh nettle leaves to the affected area (i.e. counterirritation). ${ }^{12}$ The only significant side effect was transient urticarial rash. Two underpowered randomized trials of thumb pain, ${ }^{13}$ and knee pain, ${ }^{14}$ respectively, with only 1-week follow-up were reported. The latter study showed no significant improvement, although the side effect of stinging was considered "acceptable."14 An earlier review on this subject noted some promising in vivo and in vitro effects of stinging nettle extracts in inflammatory conditions, but noted the need for more research to determine their clinical utility. ${ }^{15}$ For example, research into its potential use in patients with rheumatoid arthritis demonstrated that stinging nettle extracts inhibit transcription factor NF- $\mathrm{BB}$, which, in turn, decreases the inducible expression of genes involved in the production of cytokines and other inflammatory factors. ${ }^{16}$ Recent in vitro experiments have suggested that perhaps lipophilic extracts of stinging nettle, given increased anti-inflammatory potency and less cytotoxicity, may be more effective anti-inflammatory agents than aqueous or alcohol extractions. ${ }^{17}$

Benign Prostatic Hypertrophy: Although earlier reviews suggested stinging nettle extracts may be useful in the treatment of mild to moderate symptoms of $\mathrm{BPH},{ }^{18-20}$ more recent reviews have noted the contradictory outcomes of individual studies and the fact that other studies suggesting efficacy were done with combination products that included stinging nettle but also several other potentially active ingredients. ${ }^{9,21,22}$ Toxicities in the studies have generally been mild. However, there does appear to be a possible basis for the potential use of these agents in $\mathrm{BPH}$ as basic studies have demonstrated antiinflammatory (via reduction of tumor necrosis factor- $\alpha$ and other inflammatory cytokines) and antiproliferative effects as well as other beneficial inhibitory actions. ${ }^{22}$

Three compelling randomized trials have been reported. Lopatkin and colleagues performed a randomized, double-blind, placebo-controlled trial of 253 evaluable male patients with lower urinary tract symptoms who were given $160 \mathrm{mg}$ of sabal fruit extract and $120 \mathrm{mg}$ of urtica root extract, in combination. There were significant improvements in symptoms based on the International Prostate Symptom Score (IPSS) in the active group, compared to placebo, at 24 weeks. The control group of patients responded to active treatment following the blinded portion of the study. Side effects did not differ between the active and placebo groups. ${ }^{23}$ Schneider et al. also found significant improvements in irritative symptoms based on IPSS in 246 patients during a randomized, double-blind, placebo-controlled multicenter study that administered $459 \mathrm{mg}$ dry extract of stinging nettle roots. Side effects and urinary infections over 1 year were fewer in the active ingredient group. ${ }^{24}$ In another double-blind, placebocontrolled study, Safarinejad found improvements in IPSS and maximum urinary flow rates at 6 months, compared to placebo, in 558 randomized patients. No side effects were reportedly observed in either group. ${ }^{25}$

Allergic Rhinitis and Asthma: In vitro studies have demonstrated a number of effects that would explain a potential role for stinging nettle extracts in the treatment of allergic rhinitis or asthma. The activities include H1-receptor inactivation and inhibition (which blocks histamine production and release); tryptase inhibition (which blocks the mast cell degranulation and subsequent cytokine/chemokine release that cause allergy symptoms); COX-1 and COX-2 inhibition (which blocks prostaglandin formation); hematopoietic prostaglandin D2 synthase (HPGDS) inhibition (which blocks prostaglandin D2 production, a primary mediator of allergic rhinitis); and others. ${ }^{26}$ Studies regarding efficacy are few, and the most widely cited study, a 
late 1980s randomized controlled trial, revealed only modest improvement in subjective measures of the 69 subjects who completed the trial. Specifically, $57 \%$ of patients rated nettles as effective in relieving allergies, and $48 \%$ said nettles were more effective than allergy medications they had used previously. ${ }^{27}$ Concern that stinging nettle plants, which produce pollen, are related to the allergy-inducing plant Parietaria judaica (called spreading pellitory or pellitory-of-the-wall and commonly nicknamed sticky-weed), a species of herbaceous perennial plant in the family Urticaceae that may actually induce allergic rhinitis, may not be founded given the lack of cross-reactivity between protein pollens of representatives of these two species. ${ }^{28}$ Experts have expressed concern for the use of stinging nettle extracts for allergic rhinitis given their potential for side effects and the availability of generally safe antihistamines. ${ }^{29}$ However, except for obvious potential adverse dermatologic effects of topical application, reported side effects of Urtica dioica products have been generally mild in most types of trials. ${ }^{9}$

Bleeding: Very preliminary studies regarding the use of stinging nettle extract, or combinations of products containing nettle extract, to inhibit bleeding or improve platelet function have yielded conflicting data thus far. ${ }^{8,30}$

Diabetes: Two recent randomized controlled trials have examined the effects of stinging nettle on subjects with type 2 diabetes mellitus. In one, $100 \mathrm{mg} / \mathrm{kg}$ daily of nettle extract did not improve insulin sensitivity but did favorably reduce inflammatory biomarkers. ${ }^{31}$ In the second study, insulin-requiring subjects took a $500 \mathrm{mg}$ capsule of nettle leaf extract every 8 hours for 3 months. This treatment significantly lowered fasting blood glucose, hemoglobin A1c values and 2-hour postprandial glucose. ${ }^{32}$ Nettle leaves reportedly demonstrate insulin secretagogue, PPAR $\gamma$ agonistic and $\alpha$-glucosidase inhibitory effects. ${ }^{27} \mathrm{~A}$ four-ingredient BPH herbal remedy containing an Urtica dioica extract was associated with hypoglycemia in an elderly diabetic patient. ${ }^{33}$

\section{Conclusions}

Exposure of skin to stinging nettle may result in a rapidly progressing urticarial contact dermatitis. As observed by the author, the degree of anxiety expressed by two individuals with stinging nettle dermatitis, including the one described herein, was significant. This may be an underappreciated symptom of this entity. Such anxiety is perhaps due to the rapid onset and dramatic sensory manifestations following exposure. Knowledge of the physical description of this plant and manifestations of physical contact with it may alleviate the anxiety of exposed patients and facilitate appropriate treatment and preventive measures.

Studies on preparations and extracts of stinging nettle for treatment of a variety of inflammatory and other disorders such as osteoarthritis, benign prostatic hypertrophy, allergic rhinitis and asthma, bleeding problems and diabetes have generally reported mixed findings. However, the use of lipophilic extracts of this plant for inflammatory conditions and its use in diabetic patients may merit further investigation. Although quality clinical trials are needed, they are costly and may not be pursued due to the inability to patent natural products. In addition, because natural plant chemical (phytochemical) constituents work synergistically, extracting isolated constituents in studies may alter purported outcomes, adding complexity to effective clinical trial design.

\section{Patient-Friendly Recap}

- Stinging nettle is a common wildflower that, after coming into contact with skin, can cause a rash.

- This dermatitis typically resolves on its own within 24 hours, though symptoms may be relieved sooner using cool compresses, lotions or over-the-counter allergy medicine.

- Cooked nettle has nutritional value.

- Extracts of this plant may improve inflammatory disorders such as osteoarthritis and other conditions such as diabetes, but potential benefits need to be proven in quality clinical trials.

\section{Conflicts of Interest}

None.

\section{References}

1. Chandra Sekhar J, Sandhya S, Vinod KR, Banji DK, Sudhakar K, Chaitanya RSNAKK. Plant toxins-useful and harmful effects. Hygeia J D Med. 2012;44:79-90.

2. Cummings AJ, Olsen M. Mechanism of action of stinging nettles. Wilderness Environ Med. 2011;22:136-9. CrossRef 
3. Carpenter A. A nettlesome question. Wisconsin Natural Resources magazine. (June 2005). http://www.dnr.wi.gov/ wnrmag/html/stories/2005/jun05/nettle.htm. Accessed Sept. 3, 2015.

4. Fowler ME. Emergency veterinary medicine. In: Auerbach PS (ed). Wilderness Medicine, Sixth Edition. Philadelphia: Elsevier Mosby, 2012, pp. 1198-1221.e1.

5. Anderson BE, Miller CJ, Adams DR. Stinging nettle dermatitis. Am J Contact Dermat. 2003;14:44-6. CrossRef

6. Oliver F, Amon EU, Breathnach A, et al. Contact urticaria due to the common stinging nettle (Urtica dioica)--histological, ultrastructural and pharmacological studies. Clin Exp Dermatol. 1991;16:1-7. CrossRef

7. Uslu S, Bulbul A, Diler B, Bas EK, Nuhoglu A. Urticaria due to Urtica dioica in a neonate. Eur J Pediatr. 2011;170:401-3. CrossRef

8. American Academy of Pediatrics. Splinters and other foreign bodies in the skin (last updated 2015 Nov 21). http://www. healthychildren.org/English/health-issues/conditions/skin/ pages/Splinters-and-Other-Foreign-Bodies-in-the-Skin.aspx. Accessed October 28, 2015.

9. Natural Medicines. Stinging nettle (last updated 2015 Feb 16). https://naturalmedicines.therapeuticresearch.com/databases/ food,-herbs-supplements/professional.aspx?productid=664. Accessed October 28, 2015.

10. Guil-Guerrero JL, Rebolloso-Fuentes MM, Torija Isasa ME. Fatty acids and carotenoids from stinging nettle (Urtica dioica L.). J Food Compost Anal. 2003;16:111-9. CrossRef

11. Cameron M, Chrubasik S. Topical herbal therapies for treating osteoarthritis. Cochrane Database Syst Rev. 2013;5:CD010538. CrossRef

12. Randall C, Meethan K, Randall H, Dobbs F. Nettle sting of Urtica dioica for joint pain-an exploratory study of this complementary therapy. Complement Ther Med. 1999;7:126-31. CrossRef

13. Randall C, Randall H, Dobbs F, Hutton C, Sanders H. Randomized controlled trial of nettle sting for treatment of base-of-thumb pain. J R Soc Med. 2000;93:305-9.

14. Randall C, Dickens A, White A, Sanders H, Fox M, Campbell J. Nettle sting for chronic knee pain: a randomised controlled pilot study. Complement Ther Med. 2008;16:66-72. CrossRef

15. Chrubasik JE, Roufogalis BD, Wagner H, Chrubasik SA. A comprehensive review on nettle effect and efficacy profiles. Part I: Herba urticae. Phytomedicine. 2007;14:423-35. CrossRef

16. Riehemann K, Behnke B, Schulze-Osthoff K. Plant extracts from stinging nettle (Urtica dioica), an antirheumatic remedy, inhibit the proinflammatory transcription factor NF- $\mathrm{BB}$. FEBS Lett. 1999;442:89-94. CrossRef

17. Johnson TA, Sohn J, Inman WD, Bjeldanes LF, Rayburn K. Lipophilic stinging nettle extracts possess potent antiinflammatory activity, are not cytotoxic and may be superior to traditional tinctures for treating inflammatory disorders. Phytomedicine. 2013;20:143-7. CrossRef

18. Lowe FC, Fagelman E. Phytotherapy in the treatment of benign prostatic hyperplasia. Curr Opin Urol. 2002;12:15-8. CrossRef
19. Dvorkin L, Song KY. Herbs for benign prostatic hyperplasia. Ann Pharmacother. 2002;36:1443-52. CrossRef

20. Yarnell E. Botanical medicines for the urinary tract. World $J$ Urol. 2002;20:285-93.

21. Chrubasik JE, Roufogalis BD, Wagner H, Chrubasik S. A comprehensive review on the stinging nettle effect and efficacy profiles. Part II: Urticae radix. Phytomedicine. 2007;14:568-79. CrossRef

22. Cheetham PJ. Role of complimentary therapy for male LUTS. Curr Urol Rep. 2013;14:606-13. CrossRef

23. Lopatkin N, Sivkov A, Walther C, et al. Long-term efficacy and safety of a combination of sabal and urtica extract for lower urinary tract symptoms - a placebo-controlled, double-blind, multicenter trial. World J Urol. 2005;23:139-46. CrossRef

24. Schneider T, Rübben H. [Stinging nettle root extract (Bazotonuno) in long term treatment of benign prostatic syndrome (BPS). Results of a randomized, double-blind, placebo controlled multicenter study after 12 months]. Urologe A. 2004;43:302-6. CrossRef

25. Safarinejad MR. Urtica dioica for treatment of benign prostatic hyperplasia: a prospective, randomized, double-blind, placebocontrolled, crossover study. J Herb Pharmacother. 2005;5(4):1-11. CrossRef

26. Roschek B Jr, Fink RC, McMichael M, Alberte RS. Nettle extract (Urtica dioica) affects key receptors and enzymes associated with allergic rhinitis. Phytother Res. 2009;23:920-6. CrossRef

27. Mittman P. Randomized, double-blind study of freeze-dried Urtica dioica in the treatment of allergic rhinitis. Planta Med. 1990;56:44-7.

28. Vega-Maray AM, Fernández-González D, Valencia-Barrera R, Suárez-Cervera M. Allergenic proteins in Urtica dioica, a member of the Urticaceae allergenic family. Ann Allergy Asthma Immunol. 2006;97:343-9. CrossRef

29. Bielory L. Complementary and alternative interventions in asthma, allergy, and immunology. Ann Allergy Asthma Immunol. 2004;93(2 Suppl 1):S45-54. CrossRef

30. Hollands WJ, Saha S, Hayran O, et al. Lack of effect of bioactive-rich extracts of pomegranate, persimmon, nettle, dill, kale and Sideritis and isolated bioactives on platelet function. J Sci Food Agric. 2013;93:3588-94. CrossRef

31. Namazi N, Esfanjani AT, Heshmati J, Bahrami A. The effect of hydro alcoholic nettle (Urtica dioica) extracts on insulin sensitivity and some inflammatory indicators in patients with type 2 diabetes: a randomized double-blind control trial. Pak J Biol Sci. 2011;14:775-9. CrossRef

32. Kianbakht S, Khalighi-Sigaroodi F, Dabaghian FH. Improved glycemic control in patients with advanced type 2 diabetes mellitus taking Urtica dioica leaf extract: a randomized doubleblind placebo-controlled clinical trial. Clin Lab. 2013;59:1071-6. CrossRef

33. Edgcumbe DP, McAuley D. Hypoglycaemia related to ingestion of a herbal remedy. Eur J Emerg Med. 2008;15:236-7. CrossRef

(C) 2016 Aurora Health Care, Inc. 